\title{
Electrochemical molecularly imprinted polymers as material for pollutant detection
}

\section{Udomsap, Dutduan}

\author{
2018-12
}

Udomsap , D , Bisset , H, Culioli , G, Dollet , P , Laatikainen , K, Siren , H M M \& Branger , C 2018 , ' Electrochemical molecularly imprinted polymers as material for pollutant detection ' , Materials Today Communications, vol. 17 , pp. 458-465 . https://doi.org/10.1016/j.mtcomm.2018.10.019

http://hdl.handle.net/10138/320819

https://doi.org/10.1016/j.mtcomm.2018.10.019

cc_by_nc_nd

acceptedVersion

Downloaded from Helda, University of Helsinki institutional repository.

This is an electronic reprint of the original article.

This reprint may differ from the original in pagination and typographic detail.

Please cite the original version. 


\section{Electrochemical molecularly imprinted polymers as material for pollutant detection}

Dutduan Udomsap $^{\mathrm{a}}$, Hugues Brisset ${ }^{\mathrm{a}^{*}}$, Gérald Culioli ${ }^{\mathrm{a}}$, Pascal Dollet ${ }^{\mathrm{b}}$, Katri Laatikainen ${ }^{\mathrm{c}}$, Heli Siren $^{\mathrm{d}}$ and Catherine Branger ${ }^{\mathrm{a}^{*}}$

a Laboratoire MAPIEM, E.A.4323, Université de Toulon, CS 60584, 83041 Toulon Cedex 9, France

b Société du Canal de Provence, Le Tholonet CS70064, 13182 Aix-en-Provence Cedex 5, France.

c Lappeenranta University of Technology Department of Computation and Process Engineering,, P.O. Box 20, FI-53851 Lappeenranta, Finland

${ }^{\mathrm{d}}$ University of Helsinki, Department of Chemistry, A.I. Virtasen Aukio 1 (PO Box 55), FI00014 University of Helsinki, Helsinki, Finland

Keywords: electrochemistry, molecularly imprinted polymer, ferrocene, benzo(a)pyrene 


\begin{abstract}
New electrochemical molecularly imprinted polymers (e-MIPs) for benzo(a)pyrene $(\mathrm{BaP})$ based on vinylferrocene $(\mathrm{VFc})$ as redox tracer directly integrated into binding cavities during polymerization with crosslinker are reported. Impacts on the $\mathrm{BaP}$ detection are discussed according to: 1) the addition or no of 4-vinylpyridine (4VP) as comonomer, 2) the use of ethylene glycol dimethacrylate (EDMA) or divinylbenzene (DVB) as crosslinker.

After characterization, these new e-MIPs and their corresponding non-imprinted polymers (eNIPs) were incorporated in carbon paste electrodes and measurements were carried out by square wave voltammetry. All analyses revealed that e-MIP based on VFc and EDMA is the best to detect the template, with an imprinting factor of 7.3 and a LOD of $0.93 \mu \mathrm{mol} / \mathrm{L}$ of $\mathrm{BaP}$.
\end{abstract}

\title{
1. Introduction
}

Research on molecularly imprinted polymers (MIPs) is currently a topic of intensive investigations due to their recognition properties, their easy synthesis and their high stability [1,2]. Such polymers are frequently described as "plastic antibodies" due to their high selectivity [3]. MIPs are prepared by copolymerization of a crosslinker and a functional monomer interacting with a template [4,5]. The removal of the template from the polymer network generates complementary sites that have specific interactions with the template and its analogs.

In this context, MIPs are of great interest for development of sensors due to their high potential as stable recognition elements, and in particular in electrochemical sensors [6,7]. Since few years, we develop electrochemical molecularly imprinted polymers (e-MIPs) with a redox tracer as functional monomer directly integrated inside binding cavities during the copolymerization with the crosslinker. By this way, redox binding cavities are obtained and can be used for sensing applications [8]. Initially, this new strategy was developed to detect benzo(a)pyrene $(\mathrm{BaP})$ by the introduction of a ferrocenyl monomer whose cyclopentadienyl rings could generate aromatic stacking interactions with BaP [9]. Recently, we extended this strategy to e-MIP for bisphenol A (BPA) and integrated these new e-MIPs in screen printed electrodes. A limit of detection of $0.06 \mathrm{nmol} / \mathrm{L}$ of BPA was obtained [10,11]. This strategy has also been taken up to detect vancomycin, an antibiotic target, with electroactive MIPs prepared by solid-phase synthesis with different amounts of $\mathrm{VFc}$ and ferrocenylmethyl 
methacrylate into polymerization mixture [12]. Recently the use of supercritical carbon dioxide as porogenic solvent has been reported to prepare ferrocenyl-based MIP for BPA [13]. By this way authors indicate a quantification of BPA in the range of $4.7-8 \mathrm{nmol} / \mathrm{L}$.

To increase the performances of the electrochemical e-MIPs for BaP detection, we describe here the evolution of the system based on the use of VFc and 4-vinylpyridine (4VP) as comonomer and ethylene glycol dimethacrylate (EDMA) or divinylbenzene (DVB) as crosslinker. 4VP monomer and DVB crosslinker were reported by Lai et al. [14] to increase the performance of MIPs in terms of imprinting factor, selectivity and adsorption capacity via $\pi-\pi$ interactions between the aromatic rings present in these compounds and in $\mathrm{BaP}$. Moreover, DVB is known to give homogeneous spherical particles by precipitation polymerization which can present an advantage to prepare carbon paste electrode [15]. To evaluate the influence of 4VP as functional comonomer and of the aromatic crosslinker DVB on e-MIP properties, three new e-MIPs (and corresponding non imprinted polymers e-NIPs) were prepared using a hybridation oven: 1) VFc as monomer with DVB as crosslinker (VFcDVB), 2) VFc and 4VP as comonomer with EDMA as crosslinker (VFc-4VP-EDMA) and 3) $\mathrm{VFc}$ and 4VP as comonomer and DVB as crosslinker (VFc-4VP-DVB). We present in this article the synthesis, characterization and electrochemical properties of these new copolymers compared to the e-MIP VFc-EDMA prepared in the same conditions.

\section{Method and materials.}

\subsection{Reagents and chemicals}

Vinylferrocene (VFc), 4-vinylpyridine (4-VP), ethylene glycol dimethacrylate (EDMA), divinylbenzene (DVB), acetylferrocene, anthracene, fluorene, phenanthrene and tetrabutylammonium hexafluorophosphate were purchased from Acros. Benzo(a)pyrene (BaP), chrysene, fluoranthene, pyrene, dibenzo(a,h)anthracene, tetrabutylammonium hexafluorophosphate (TBAFP) were purchased from Aldrich and Azobisisobutyronitrile (AIBN) from Fluka. Toluene, heptane and acetonitrile were analytical grade and purchased from VWR and used without any further purification. Ultrapure water (Millipore) was used for analysis. The quality of acetonitrile was HPLC grade.

\subsection{Synthesis}

Polymerization by precipitation was carried out in an UVP HB-100 hybridation oven with molar ratios summarized in Table 1. Functional monomer, crosslinker agent and $\mathrm{BaP}$ (in the case of MIPs) were introduced in the Pyrex glass tube (diameter of $35 \mathrm{~mm}$ and volume of 120 
$\mathrm{mL}$ ) under nitrogen gas and kept in the refrigerator at $4{ }^{\circ} \mathrm{C}$ for 30 minutes to promote the formation of functional monomer complex-BaP. Then, the solvent was added (monomer/solvent ratio is $3 \%$ by weight) and the whole mixture was degassed for 15 minutes in an ice-water bath. After the treatment the radical initiator (AIBN) was added (the ratio AIBN monomer is $2 \%$ by weight) and again the mixture was degassed for another 5 minutes under similar conditions. The reaction medium was heated in at $8 \mathrm{rpm}$ along the axis of the tube. The temperature of the oven was increased by $5{ }^{\circ} \mathrm{C}$ every 15 minutes from $30{ }^{\circ} \mathrm{C}$ to 80 ${ }^{\circ} \mathrm{C}$ and kept constant at this temperature until the end of the polymerization, at least 20 hours. The polymer was recovered by centrifugation at $10,000 \mathrm{rpm}$ and washed with a mixture of acetonitrile and toluene except for the VFc-4VP-EDMA polymers for which a mixture of heptane and toluene was used. In fact for Fc-4VP-EDMA it was impossible to have precipitates with a suitable yield (more $10 \%$ ) using the acetonitrile-toluene mixture. Elemental analyses, and particularly iron dosage, were made by the Central Analysis Service of the CNRS Laboratory of Solaize USR- 59C/CNRS and confirm the well integrations of monomers (Table 1). 
Table 1. Polymerization by precipitation results with the molar ratios for e-MIPs: BaP/VFc/EDMA: 1/5/25; BaP/VFc/4VP/EDMA: 1/2.5/2.5/25; $\mathrm{BaP} / \mathrm{VFc} / \mathrm{DVB}$ : 1/5/25 and BaP/VFc/4VP/DVB: 1/2.5/2.5/25. Identical conditions were used for e-NIPs without BaP.

\begin{tabular}{|c|c|c|c|c|c|c|c|c|c|c|c|c|c|c|c|}
\hline \multirow[b]{2}{*}{ Copolymer } & \multirow[b]{2}{*}{$\begin{array}{c}\mathrm{BaP} \\
(\mathrm{mmol})\end{array}$} & \multicolumn{3}{|c|}{$\begin{array}{c}\text { Quantities } \\
\text { (mmol) }\end{array}$} & \multicolumn{2}{|l|}{ Solvent } & \multirow[b]{2}{*}{$\begin{array}{c}\text { Solvent } \\
(\mathrm{mL})\end{array}$} & \multirow[b]{2}{*}{$\begin{array}{c}\text { Yield } \\
(\%)\end{array}$} & \multirow[b]{2}{*}{$\begin{array}{l}\mathrm{Dn}^{\mathrm{a}} \\
(\mathrm{nm})\end{array}$} & \multirow[b]{2}{*}{$\begin{array}{l}\mathrm{CV}^{\mathrm{b}} \\
(\%)\end{array}$} & \multirow[b]{2}{*}{$\begin{array}{c}\mathrm{S}_{\mathrm{BET}} \\
\left(\mathrm{m}^{2} / \mathrm{g}\right)\end{array}$} & \multirow[b]{2}{*}{$\begin{array}{c}\mathrm{Vp} \\
\left(\mathrm{cm}^{3} / \mathrm{g}\right)\end{array}$} & \multicolumn{3}{|c|}{ Elemental analysis } \\
\hline & & $\mathrm{VFc}$ & $4-\mathrm{VP}$ & $\begin{array}{c}\text { EDMA } \\
\text { or } \\
\text { DVB }\end{array}$ & $\begin{array}{c}\text { Acetonitrile } \\
\text { (ACN) } \\
\text { or } \\
\text { Heptane (HP) }\end{array}$ & Toluene & & & & & & & $\begin{array}{c}\alpha \mathrm{VFc} \\
(\% \mathrm{~mol})\end{array}$ & $\begin{array}{c}\alpha 4 \mathrm{VP} \\
(\% \mathrm{~mol})\end{array}$ & $\begin{array}{c}\alpha \mathrm{EDMA} \\
\text { or } \alpha \mathrm{DVB} \\
(\% \mathrm{~mol})\end{array}$ \\
\hline $\begin{array}{c}\text { e-MIP } \\
\text { VFc-EDMA }\end{array}$ & 0.32 & 1.60 & 0 & 8 & $70(\mathrm{ACN})$ & 30 & 100 & 59 & $580 \pm 170$ & 29 & 14.6 & 0.022 & 19 & l & $81(83)^{d}$ \\
\hline $\begin{array}{c}\text { e-NIP } \\
\text { VFc-EDMA }\end{array}$ & 0 & 1.60 & 0 & 8 & $70(\mathrm{ACN})$ & 30 & 100 & 80 & $210 \pm 60$ & 29 & 43.8 & 0.153 & 18 & l & $82(83)^{d}$ \\
\hline $\begin{array}{c}\text { e-MIP } \\
\text { VFc-4VP-EDMA }\end{array}$ & 0.24 & 0.60 & 0.6 & 6 & 95 (HP) & 5 & 60 & 40 & nd & nd & 241.5 & 0.132 & 8 & 8 & $84(84)^{\mathrm{d}}$ \\
\hline $\begin{array}{c}\text { e-NIP } \\
\text { VFc-4VP-EDMA }\end{array}$ & 0 & 0.60 & 0.6 & 6 & 95 (HP) & 5 & 60 & 40 & nd & nd & 93.7 & 0.225 & 8 & 8 & $84(84)^{d}$ \\
\hline $\begin{array}{c}\text { e-MIP } \\
\text { VFc-DVB }\end{array}$ & 0.35 & 1.75 & 0 & 8.75 & $95(\mathrm{ACN})$ & 5 & 70 & 30 & $220 \pm 40$ & 19 & 125.1 & 0.258 & 9 & l & $91(83)^{d}$ \\
\hline $\begin{array}{c}\text { e-NIP } \\
\text { VFc-DVB }\end{array}$ & 0 & 1.75 & 0 & 8.75 & $95(\mathrm{ACN})$ & 5 & 70 & 40 & $250 \pm 90$ & 37 & nd & nd & 9 & l & $91(83)^{d}$ \\
\hline $\begin{array}{c}\text { e-MIP } \\
\text { VFc-4VP-DVB }\end{array}$ & 0.40 & 1 & 1 & 10 & $95(\mathrm{ACN})$ & 5 & 70 & 26 & $300 \pm 150$ & 49 & 298.2 & 0.161 & 2 & 11 & $87(84)^{d}$ \\
\hline $\begin{array}{c}\text { e-NIP } \\
\text { VFc-4VP-DVB }\end{array}$ & 0 & 1 & 1 & 10 & $95(\mathrm{ACN})$ & 5 & 70 & 28 & $570 \pm 240$ & 43 & nd & nd & 3 & 11 & $86(84)^{d}$ \\
\hline
\end{tabular}

${ }^{\mathrm{a}}$ The average particle diameter (Dn) is determined from SEM images taken at 100 particles and using SmarTiff software.

${ }^{\mathrm{b}}$ Coefficient of variation $(\mathrm{CV})$ is defined by the average particle size of the standard deviation $(\mathrm{CV} \%=\mathrm{Dn} \times 100 / \sigma)$

nd $=$ not determined

d Theoretical values 
E-MIPs and e-NIPs were analyzed by scanning electron microscopy (SEM) with Gemini ${ }^{\circledR}$ Supra 40VP apparatus. Small amount of polymer was deposed on a SEM support and metalized with gold. The images were registered under the following conditions: $3 \mathrm{kV}$, secondary electron detector, diaphragm 30 . Average particle diameters $\left(D_{n}\right)$ were determined from SEM images taken at 100 particles and using SmarTiff software and coefficient of variation $(\mathrm{CV})$ defined by the average particle size of the standard deviation (equation 1$). \mathrm{D}_{\mathrm{n}}$ and CV values are summarized in Table 1.

$$
C V=\frac{\text { Standard deviation }}{\text { average diameter }} \times 100=\frac{\left(\sqrt{\frac{\sum\left(d-D_{n}\right)^{2}}{N}}\right)}{D_{n}} \times 100 \quad \text { [Equation 1] }
$$

Brunauer-Emmett-Teller (BET) analyses were carried on a Gemini 2380 apparatus from Micrometrics.

Thermal analyzes were performed on a SDT Q600 from TA Instruments and thermograms were treated from the Universal Analysis software (TA Instruments). The heat made program consists of two steps: 1) an isotherm of 10 minutes at $25^{\circ} \mathrm{C}$ to stabilize the measuring cell and 2) a ramp from $25^{\circ} \mathrm{C}$ to $900{ }^{\circ} \mathrm{C}$ at a rate of $20^{\circ} \mathrm{C} / \mathrm{min}$ under nitrogen.

\subsection{Quantification of BaP by HPLC-UV}

All separations were achieved on using an isocratic system when only BaP was present or a gradient system for the mixtures of several Polycyclic Aromatic Hydrocarbons (PAHs) (fluorene, fluoranthene, anthracene, phenanthrene, chrysene, pyrene, and dibenzo(a,h)anthracene). The former consisted of pure acetonitrile while the latter consisted of a mixture of acetonitrile-water starting with $55 \%$ acetonitrile for 10 minutes, then ascending linearly to $100 \%$ acetonitrile within 25 minutes, and being maintained for 20 minutes before finally dropped down to $55 \%$ within 5 minutes. In each case, the flow rate was fixed at $0.5 \mathrm{~mL} / \mathrm{min}$ and a $50 \mu \mathrm{L}$ sample volume was injected into the chromatographic system.

Calibration curves at $\lambda=296 \mathrm{~nm}$ were obtained using a series of standard solutions containing mixture of PAHs at five different concentrations. Three replicated injections for each concentration were made to ensure accurate and reproducible responses. Linearity was evaluated by using least square method. The theoretical limits of detection (LOD) at a signal/noise ratio of 3 and theoretical limits of quantification (LOQ) at a signal/noise ratio of 
10 for all PAHs were in the range of $0.04-0.79$ and $0.13-2.64 \mu \mathrm{g} / \mathrm{L}$, respectively.

\subsection{Batch binding experiments}

$10 \mathrm{mg}$ of polymer were placed in a $30 \mathrm{~mL}$ glass vial and mixed with $10 \mathrm{~mL}$ of $\mathrm{BaP}$ solution of different concentrations varying from 0.01 to $10 \mathrm{mg} / \mathrm{L}$. BaP solutions were prepared in water/acetonitrile $(99 / 1, \mathrm{v} / \mathrm{v})$. Then the vial was shaken under horizontal stirring at $200 \mathrm{rpm}$ at room temperature until equilibrium ( 24 hours). The supernatants were collected. The amounts of adsorbed $\mathrm{BaP}$ were calculated by subtracting the supernatant concentrations from the initial concentrations of $\mathrm{BaP}$ in solution (Equation 2). The imprinting factor was determined as the ratio between the maximum binding capacity of the e-MIP and that of the e-NIP (Equation 3). The binding isotherm experiment was carried out in duplicate.

$$
\begin{gathered}
\mathrm{Q}=\frac{\text { adsorbed quantity }(\mathrm{mg} \text { or } \mu \mathrm{mol})}{\text { polymer weight }(\mathrm{g})} \\
\text { or } Q=\frac{\text { [Equation 2] }}{\text { polymer weight }(\mathrm{g})} \\
\mathrm{IF}=\frac{Q, e-M I P}{Q, e-N I P}
\end{gathered}
$$

\subsection{Cross-selectivity experiments}

The binding isotherm experiments were carried out in duplicate. For cross-selectivity, experiment $10 \mathrm{mg}$ of polymer were placed in a $30 \mathrm{~mL}$ glass vial and mixed with $10 \mathrm{~mL}$ of solution containing BaP and one interfering PAH. The studied PAHs used were fluorene, fluoranthene, anthracene, phenanthrene, chrysene, pyrene, and dibenzo(a,h)anthracene. The concentrations of $\mathrm{BaP}$ and the interfering PAH were $0.4 \mu \mathrm{g} / \mathrm{L}$ each. The vial was then shaken horizontally at $200 \mathrm{rpm}$ at room temperature for 24 hours. The supernatant was analyzed by HPLC-UV in order to determine the equilibrium concentration of the target $\left(\mathrm{C}_{\mathrm{e}}\right)$ and the amount of analyte adsorbed by the polymer $\mathrm{Q}_{\mathrm{e}}$ (Equation 4 ) in $\mathrm{mg} / \mathrm{g}$, with $\mathrm{C}_{0}=$ initial concentration, $\mathrm{V}=$ volume of solution and $\mathrm{m}=$ mass of polymer).

$$
\mathrm{Qe}=\frac{\left(C_{0}-C_{e}\right) * V}{m}
$$


The selectivity coefficient is calculated from Equation 5.

$$
\mathrm{k}=\frac{Q_{e}(B a P) * C_{e}(P A H)}{Q_{e}(P A H) * C_{e}(B a P)}
$$

[Equation 5]

Finally, the selectivity of e-MIP can be compared to the e-NIP by the relative selectivity coefficient $\left(\mathrm{k}^{\prime}\right)$ which is the ratio of the selectivity coefficient $(\mathrm{k})$ of a MIP to that of the corresponding e-NIP: $\boldsymbol{k}^{\prime}=\frac{\boldsymbol{k}_{\mathrm{MIP}}}{\boldsymbol{k}_{\mathrm{NIP}}}$

\subsection{Electrochemistry analyses}

For electrochemistry analyses e-MIP and e-NIP were mixed with a carbon paste (Gwent group, C10903P14) (1/4, w/w). Mixtures were homogenized with a small amount of dichloromethane and filled in a hollow working $5 \mathrm{~mm}$ diameter electrode (Metrohm, RDE.BLANK 80184). The electrode was then dried under vacuum at $30^{\circ} \mathrm{C}$ overnight and the surface was polished with a sand paper. The dry polymer and carbon paste weighed $11.4 \mathrm{mg}$. The working electrode containing polymer was then placed in an electrolytic cell in presence of a reference electrode $\left(\mathrm{Hg} / \mathrm{Hg}_{2} \mathrm{Cl}_{2} / \mathrm{KCl}\right.$ sat) and a counter electrode ( $\mathrm{Pt}, 1 \mathrm{~mm}$ diameter). The electrolyte used was $0.1 \mathrm{M}$ tetrabutylammonium hexafluorophosphate in acetonitrile. The solution was purged 5 minutes with an argon flow. The blank measurement was registered after 30 minutes of electrode submersion in order to get a stabilized signal. Then $100 \mu \mathrm{L}$ of $\mathrm{BaP}$ solution at $0.2 \mathrm{mg} / \mathrm{L}$ was added into the electrolyte solution. Square Wave Voltammetry (SWV) parameters vs SCE are: Initial potential (EI): $0.0 \mathrm{~V}$; Vertex potential (EV): $1.0 \mathrm{~V}$; Final potential (EF): $0.0 \mathrm{~V}$; Pulse (PH/PW): $0.05 \mathrm{~V}$; Pulse duration: $50 \mathrm{~ms}$; Pulse height (SH): $5 \mathrm{mV}$; Scan rate: $20 \mathrm{mV} / \mathrm{s}$.

\section{Results}

\subsection{Synthesis and characterizations of e-MIPs and e-NIPs}

Particles of e-MIPs and e-NIPs were prepared by precipitation polymerization. This convenient process requires to use a solvent, or mixture of solvents, in which the monomers, the initiator and the template molecule are initially soluble. To form particles, the choice of the solvent is primordial since it must allow the precipitation of growing chains. In order to achieve this, mixtures of acetonitrile/toluene were used for VFc-EDMA and DVB based polymers (70/30 and 95/5 respectively). However, as far as VFc, 4VP and EDMA monomers 
were concerned, the precipitation could not be resolved in any mixture based on these two solvents, regardless of their relative proportions. This was the reason why acetonitrile had to be replaced by heptane.

SEM pictures revealed that, for polymers with DVB as crosslinker, well defined beads with diameters were obtained with sizes varying from 220 to $570 \mathrm{~nm}$ (Figure 1). The use of EDMA as crosslinker for VFc-EDMA system led to aggregated beads in the similar size range (210 to $580 \mathrm{~nm}$ ), whereas the particles were poorly defined for VFc-4VP-EDMA system. This appears to be a drastic effect of the change of monomers and solvent (introduction of heptane) for the obtaining of particles in a spherical form via precipitation polymerization.

Elemental analyses for copolymers based on EDMA were consistent with theoretical values which confirmed the good incorporation of VFc and 4VP monomers (Table 1). On the contrary with DVB, the results showed a difference between theoretical and experimental values revealing that the VFc was not properly incorporated. George and Hayes [16] have reported that VFc lead to a degree of polymerization independent on the concentration of the initiator or a poor incorporation of this monomer with styrene. These authors did the hypothesis of an intramolecular electron transfer from the iron atom to the radical center generating an anionic end which leads to an intramolecular termination reaction [17]. This hypothesis is consistent with our results.

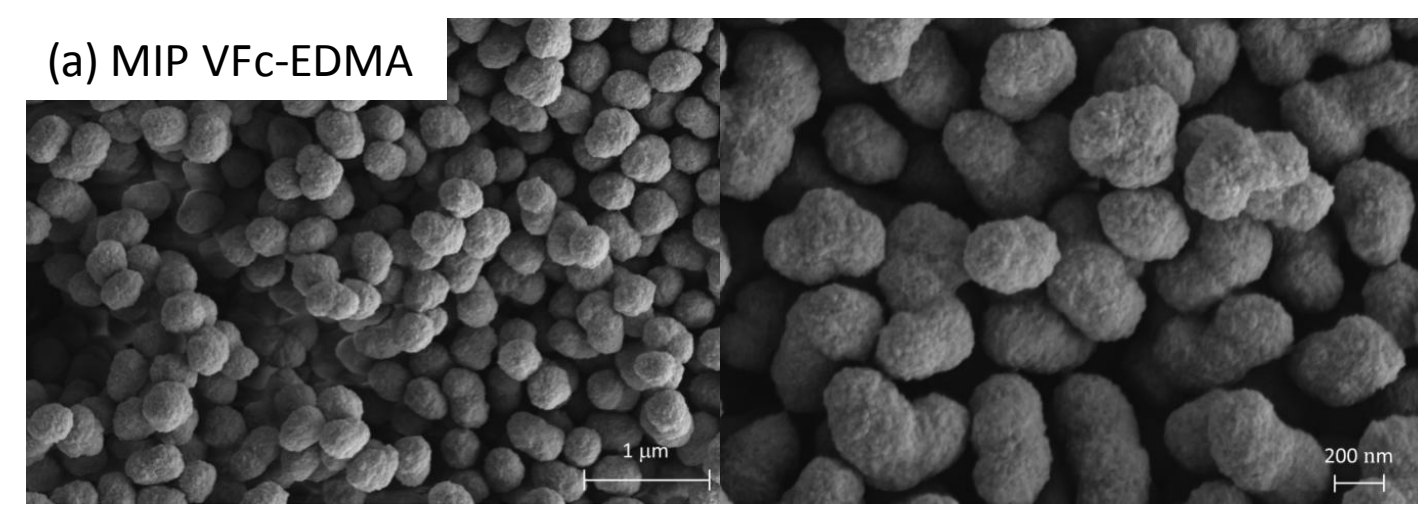

(b) NIP VFc-EDMA

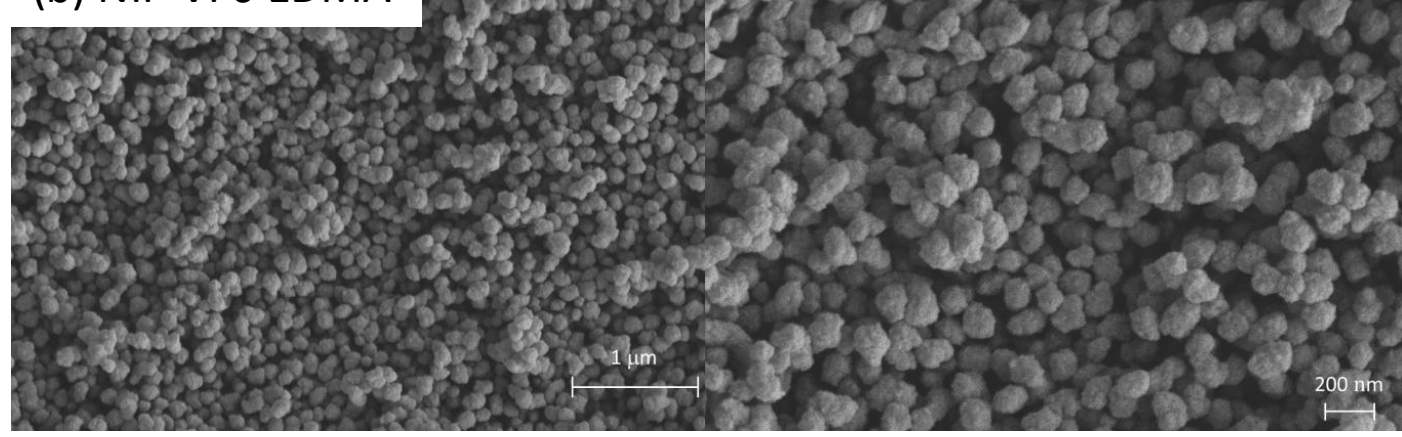



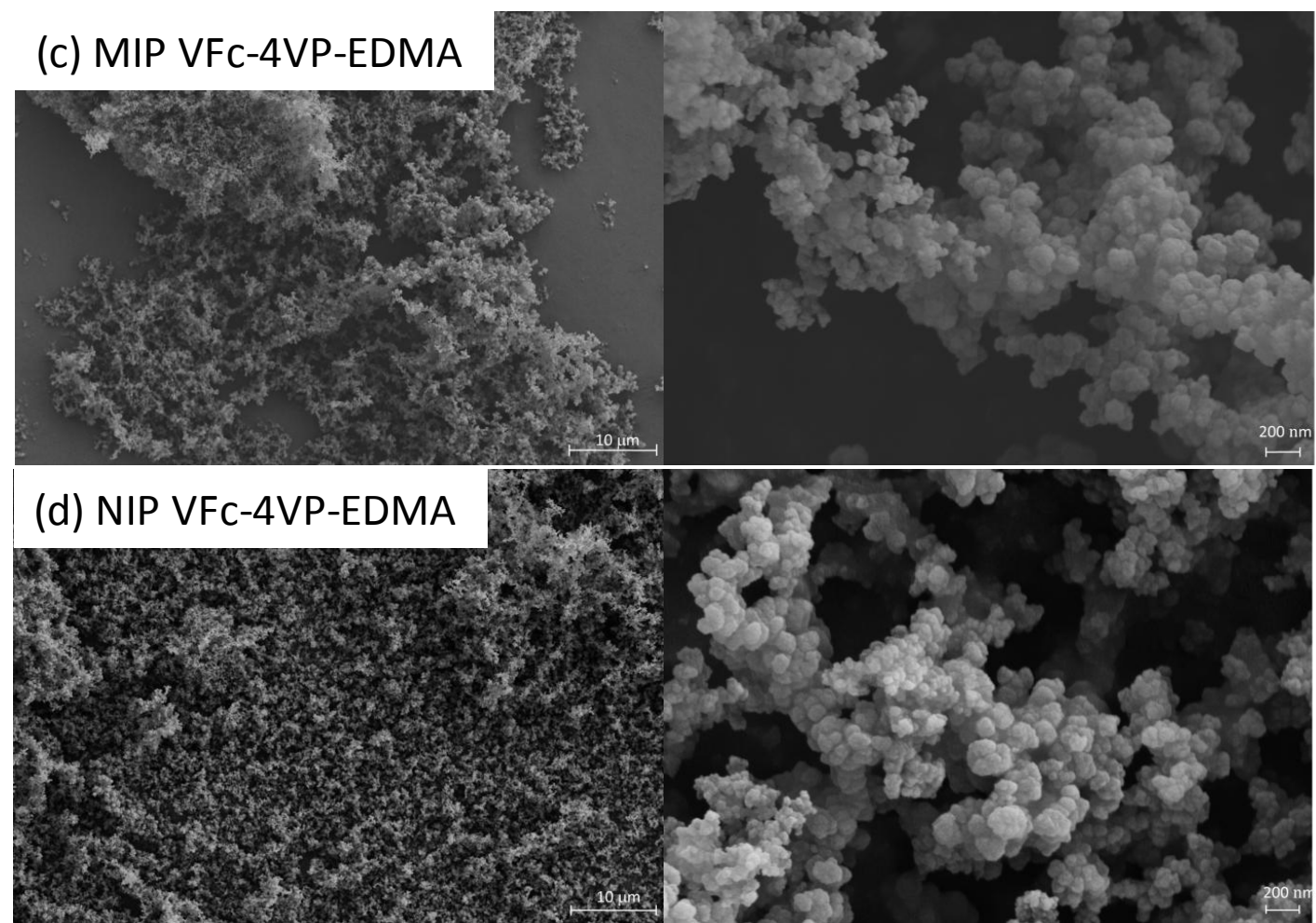

Figure 1. SEM pictures of (a) e-MIP VFc-EDMA, (b) e-NIP VFc-EDMA, (c) e-MIP VFc4VP-EDMA, (d) e-NIP VFc-4VP-EDMA.
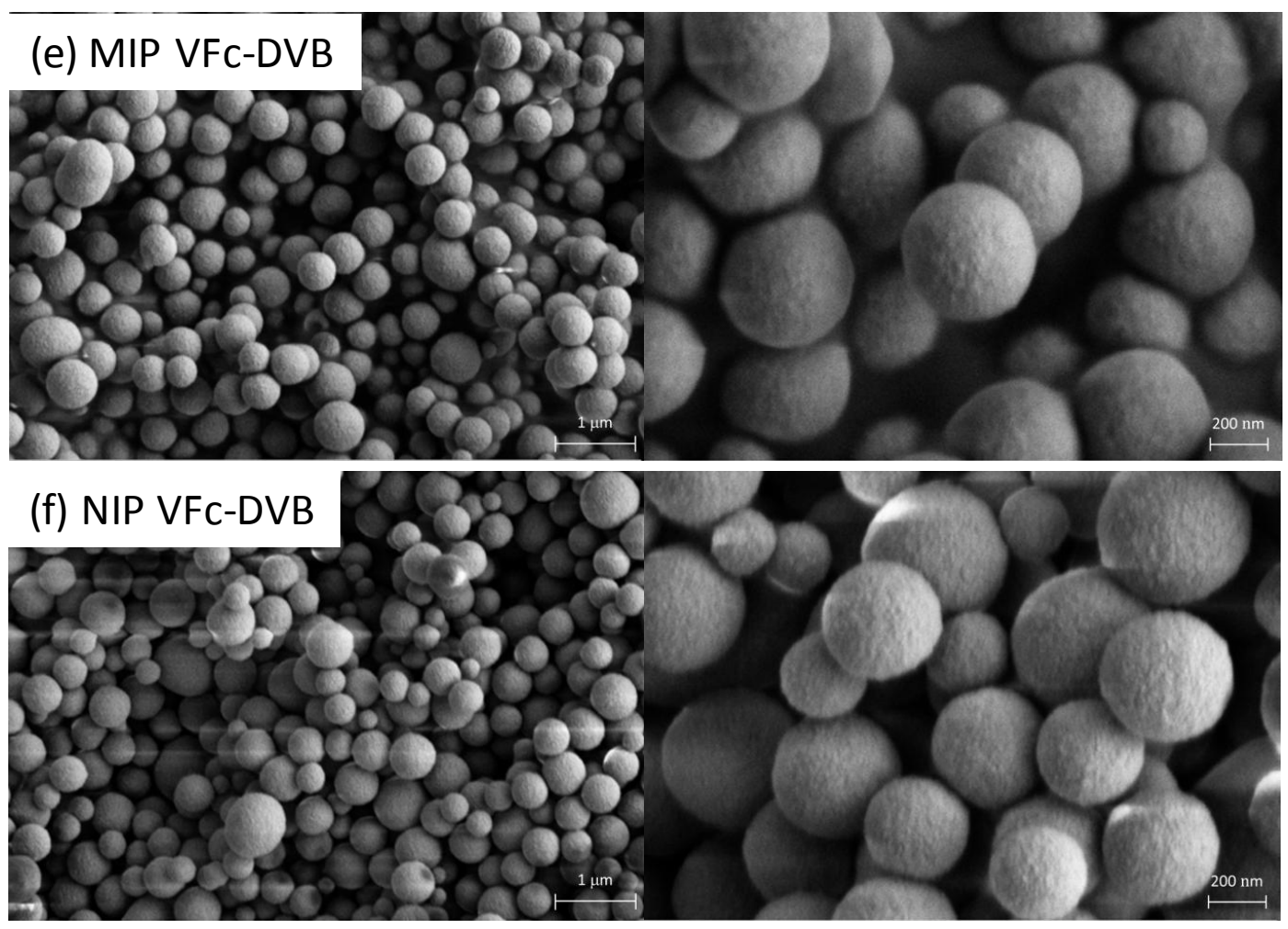


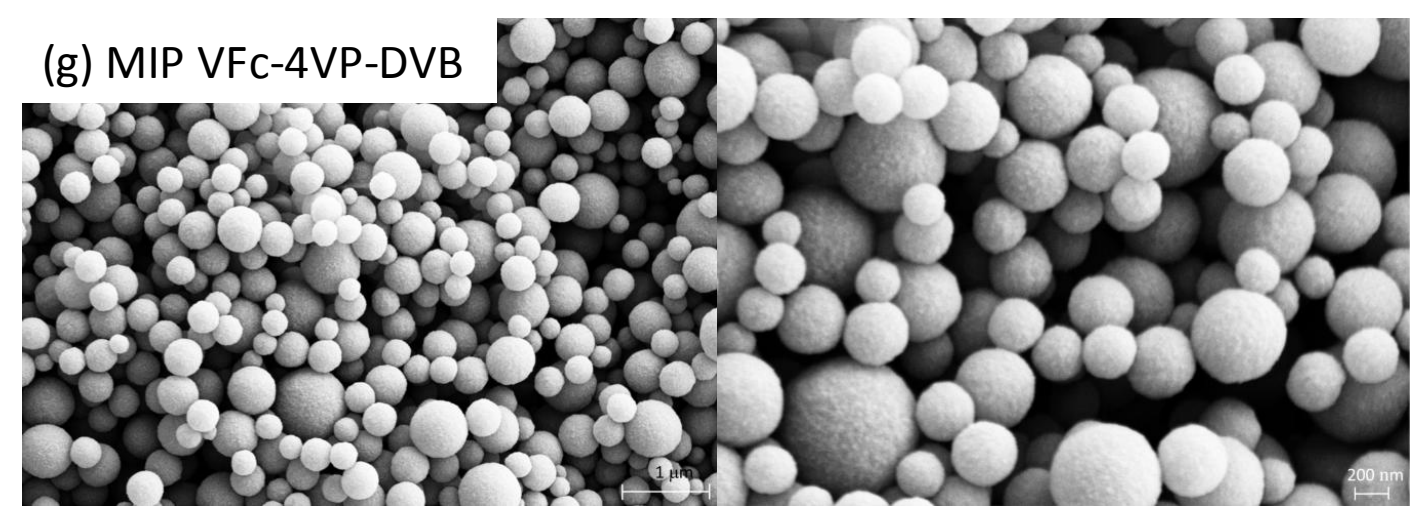

(h) NIP VFc-4VP-DVB

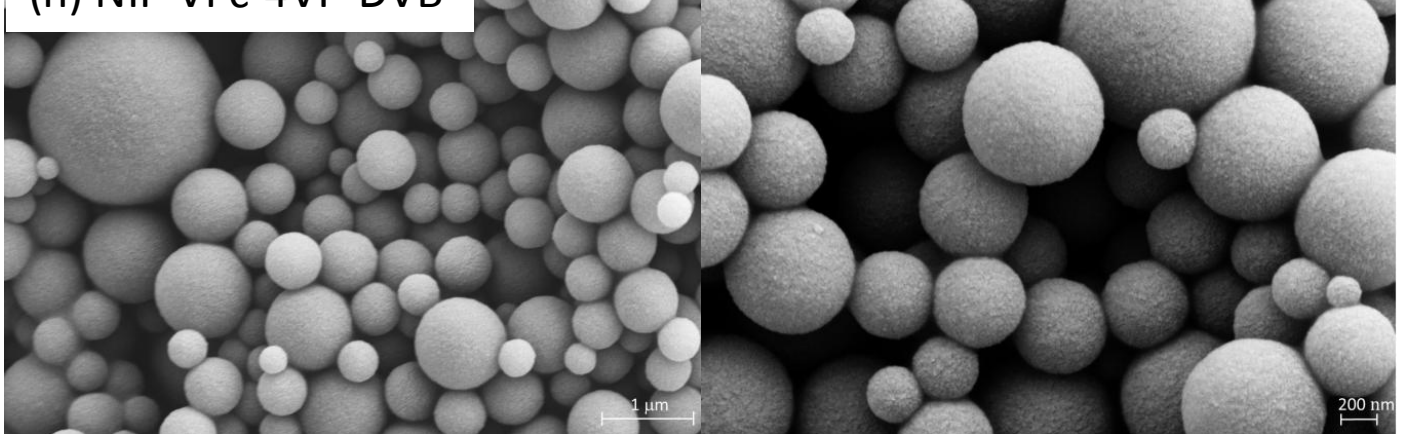

Figure 1. SEM pictures of (e) e-MIP VFc-DVB, (f) e-NIP VFc-DVB, (g) e-MIP VFc-4VP-DVB, (h) e-NIP VFc-4VP-DVB.

Thermogravimetric analyzes under nitrogen at $20{ }^{\circ} \mathrm{C} / \mathrm{min}$ indicated a similar behavior for all copolymers. The thermal degradations of VFc-EDMA and VFc-4VP-EDMA copolymers began at $250{ }^{\circ} \mathrm{C}$. DVB-based copolymers were more resistant with a beginning of degradation at $320{ }^{\circ} \mathrm{C}$ as expected for polymers integrating aromatic groups (Figure 2).
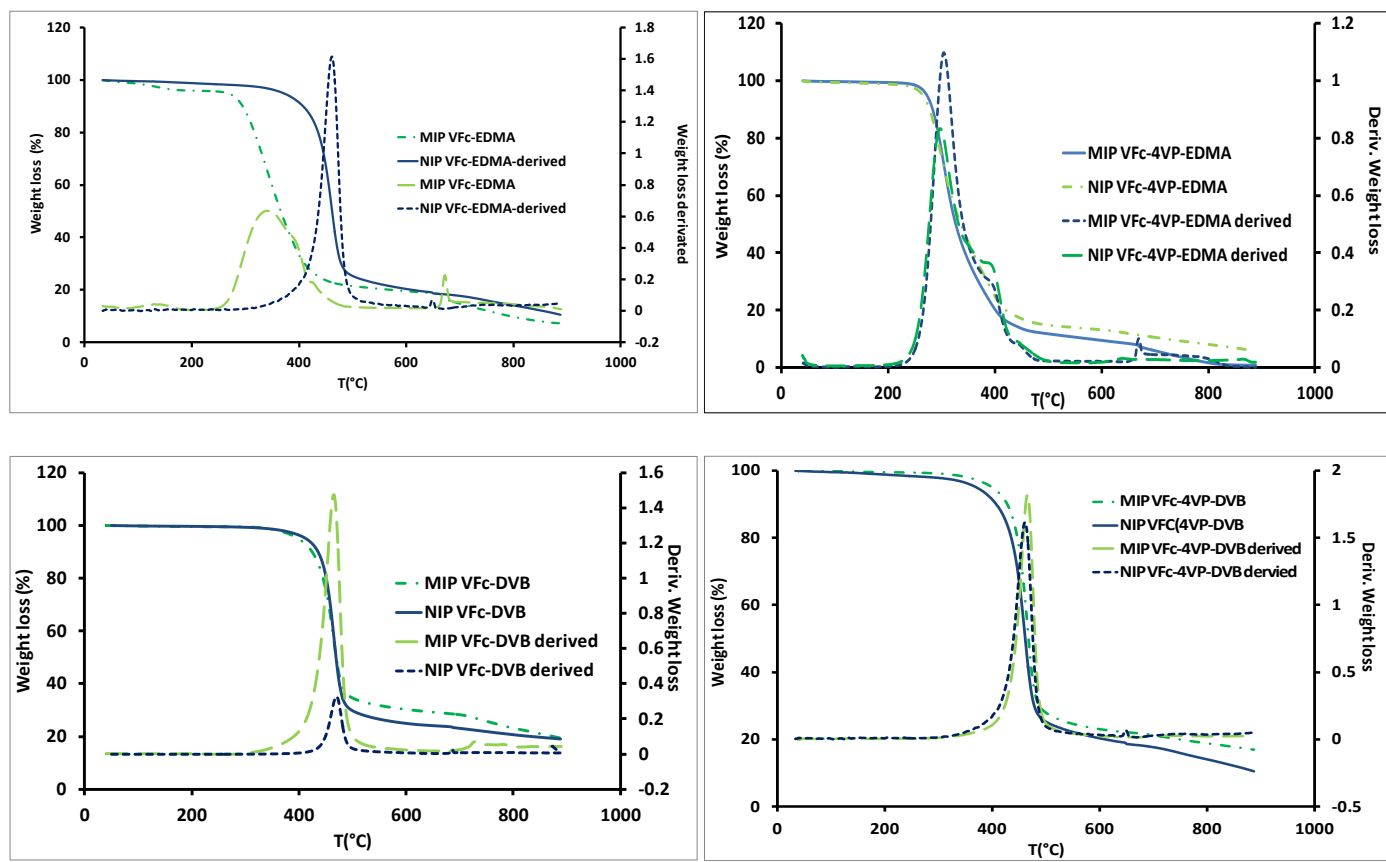
Figure 2. TGA curves in nitrogen with a heating rate of $20{ }^{\circ} \mathrm{C} / \mathrm{min}$ for e-MIP/e-NIP for VFcEDMA, VFc-4VP-EDMA, VFc-DVB and VFc-4VP-DVB.

BET analyses were carried out for all copolymers (Table 1, Figure 3). Isothermal adsorption/desorption of nitrogen for VFc-EDMA was a type I isotherm revealing that this copolymer is non porous confirmed by the close values of surface area determined experimentally. Other copolymers had type II isotherms which are characteristic of nonporous or macroporous materials. The comparison of surface area determinates from BET measurements seemed to indicate that addition of $4 \mathrm{VP}$ as functional comonomer increases the specific surface of copolymers. However the interpretation of these data was not easy because porosity variations may be linked to porogen solvent or monomer incorporation rate.
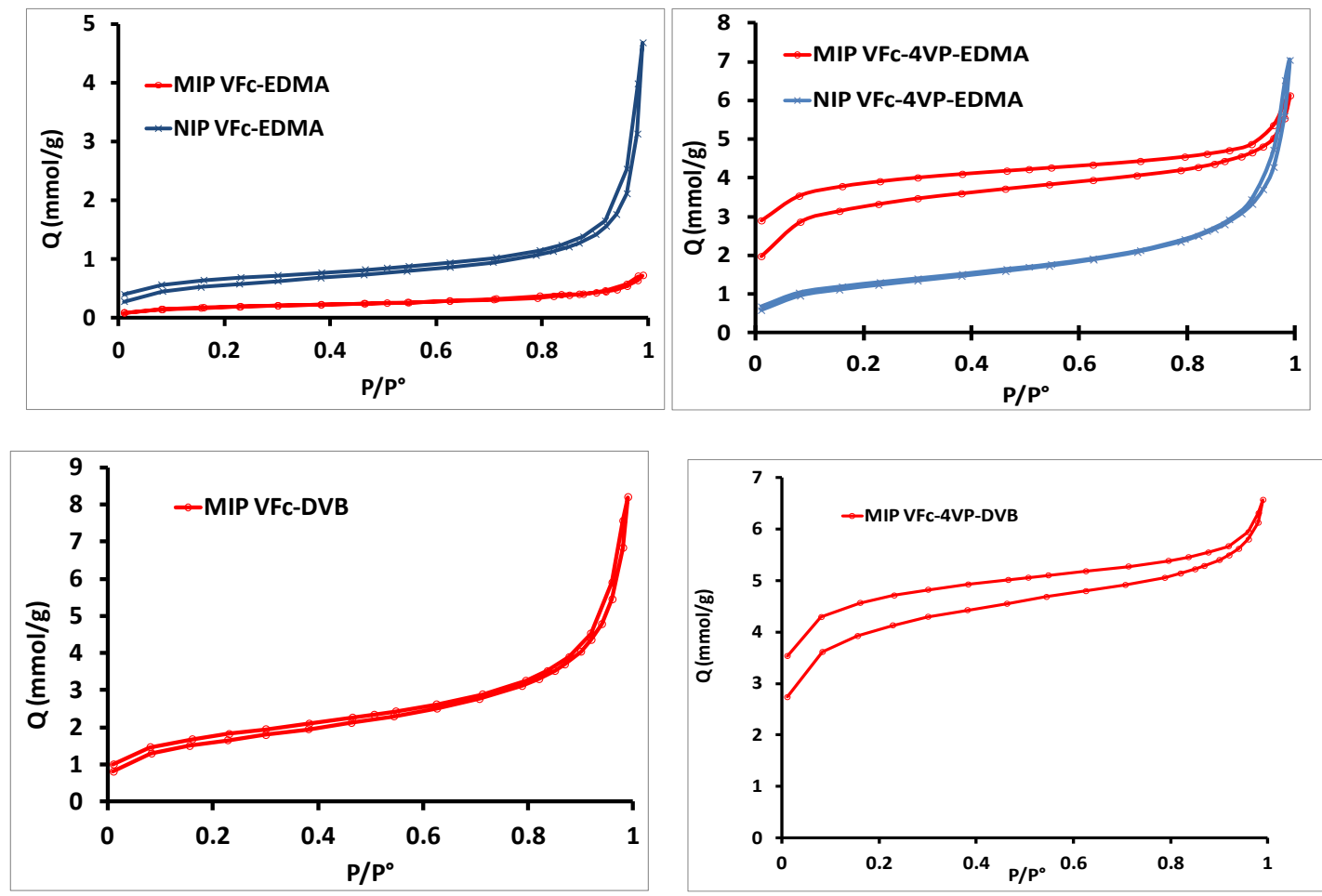

Figure 3. Nitrogen adsorption/desorption isotherms for e-MIP/e-NIP for VFc-EDMA and VFc-4VP-EDMA, e-MIP VFc-DVB and VFc-4VP-DVB.

\subsection{Binding properties}

The binding properties of $\mathrm{BaP}$ were investigated in an aqueous rich medium (water/acetonitrile $(99: 1, \mathrm{v} / \mathrm{v})$ ) in batch mode. Retention of BaP increased sharply in the early hours to lead at a maximum and constant after 6 hours contact time until the end of the experiment to 24 hours. Isotherms curves of e-MIP/e-NIP copolymers for VFc-EDMA, VFc- 
DVB and VFc-4VP-DVB can be treated to type L isothermal (Figure 4) $[18,19]$.
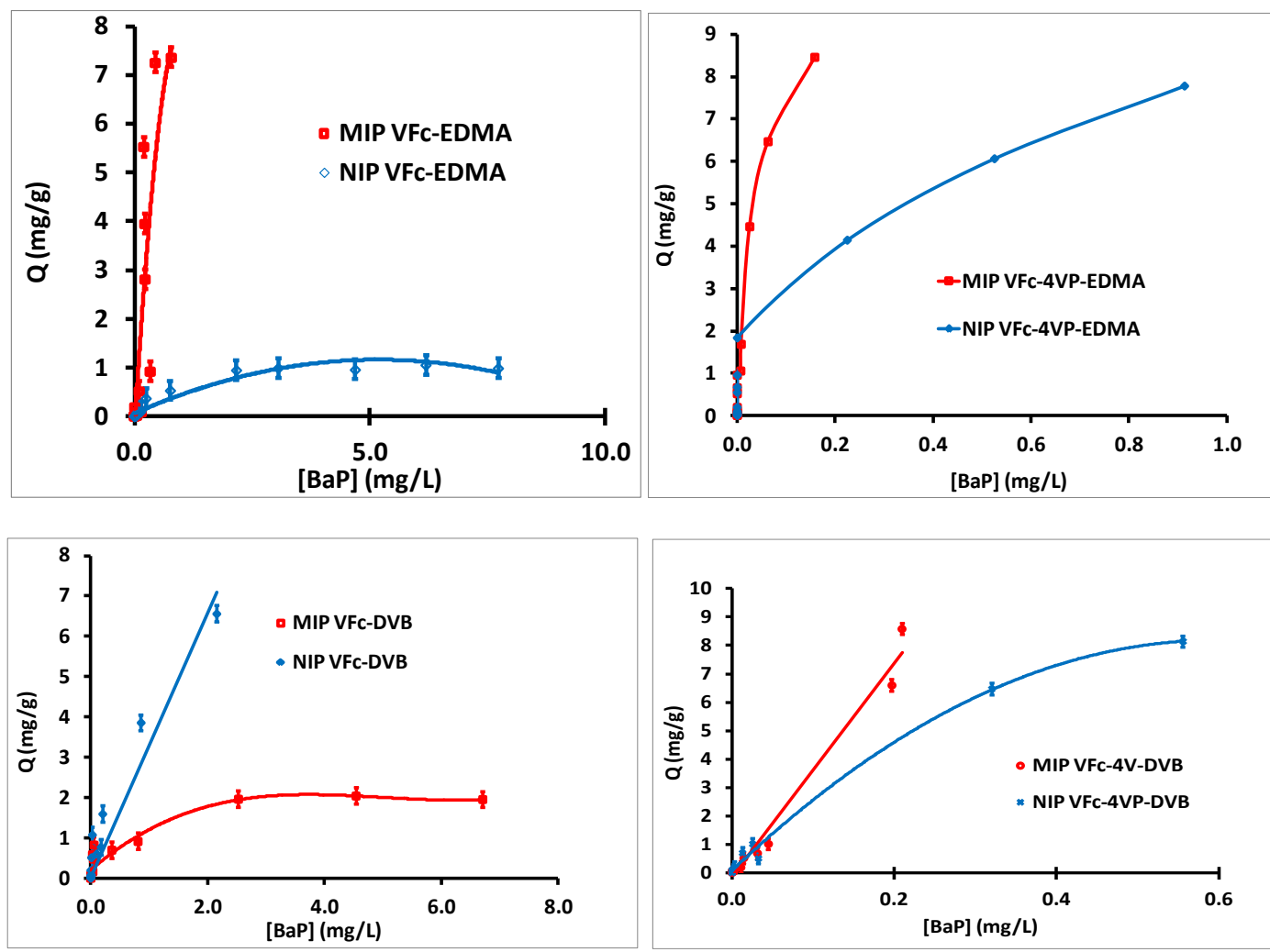

Figure 4. Adsorption isotherms of e-MIPs/e-NIPs for VFc-EDMA, VFc-4VP-EDMA, VFcDVB and VFc-4VP-DVB depending on the equilibrium concentration $(\mathrm{Ce})$ of $\mathrm{BaP}$ in water/acetonitrile 99/1 (v/v).

In this case, the ratio between the adsorption capacity and the concentration of the remaining target (concentration at the equilibrium, $\mathrm{C}_{\mathrm{e}}$ ) decreases when the target concentration increases. VFc-4VP-EDMA e-MIP and e-NIP presented $\mathrm{H}$ type isotherms which are a special case of L type isotherms having a very high initial slope. The low solubility of $\mathrm{BaP}$ in water/acetonitrile 99/1 water did not allow to reach the plateau. In these conditions, adsorption capacities were determined as the maximum values reached on isotherms and (Table 2) reveal similar values for e-MIPs and e-NIPs from VFc-4VP-DVB and VFc-4VPEDMA with an imprinting factor close to 1.

Table 2. Values of adsorption capacity (Q) and imprinting factors (IF) of the different polymers.

e-MIP Polymer
e-NIP Polymer
$\mathrm{Q}(\mathrm{mg} / \mathrm{g})$
IF 


\begin{tabular}{|c|c|c|c|c|}
\hline VFc-EDMA & $7.3 \pm 0.2$ & VFc-EDMA & $1.0 \pm 0.2$ & 7.3 \\
\hline VFc-4VP-EDMA & $8.5+0.2$ & VFc-4VP-EDMA & $7.8+0.2$ & 1.1 \\
\hline VFc-DVB & $2.0 \pm 0.2$ & VFc-DVB & $6.3+0.2$ & 0.3 \\
\hline VFc-4VP-DVB & $8.6+0.2$ & VFc-4VP-DVB & $8.1+0.2$ & 1.1 \\
\hline
\end{tabular}

Values for e-MIP/e-NIP from VFc-DVB copolymers indicated that e-NIP adsorb much more $\mathrm{BaP}$ compared to corresponding e-MIP revealing in this case that the synthesis of e-MIP was not needed to increase the efficiency of adsorption of $\mathrm{BaP}$. The best imprinting effect was obtained for e-MIP-VFc-EDMA with a value of 7.3. Comparison of result between the use of EDMA and DVB were consistent with studies of W. L. Ho et al [20]. These authors compared MIP based on 4VP-EDMA and 4VP-DVB for BaP and found a better adsorption capacity for MIP-4VP-DVB (20.78 $\mu \mathrm{g} / \mathrm{g}$, IF 1.34) but a better imprinting effect for MIP-4VP-EDMA (4.77 $\mu \mathrm{g} / \mathrm{g}$, IF 2.30). As expected the replacement of part of VFc by $4 \mathrm{VP}$ increased the adsorption capacity. Unfortunately, there was no improving of imprinting factor.

Cross-selectivity of e-MIPs towards other PAHs was studied by putting the imprinted and non-imprinted polymers in contact with solutions of $\mathrm{BaP}$ with one interfering $\mathrm{PAH}$ chosen between fluorene, phenanthrene, anthracene, fluoranthene, pyrene, chrysene or dibenzo(a,h)anthracene). Based on the BaP rebinding results, the study of cross-selectivity was made only on e-MIP/e-NIP VFc-EDMA copolymers. The selectivity coefficients (k) ranged from 0.03 to 2.60 for e-MIP and from 0.02 to 4.30 for e-NIP (Table 3).

Table 3. Selectivity coefficients (k) and relative selectivity coefficients (k') for each PAH with VFc-EDMA copolymer.

\begin{tabular}{|c|c|c|c|}
\cline { 2 - 3 } \multicolumn{1}{c|}{} & $\mathrm{k}$ & $\mathrm{k}$ & \multirow{2}{*}{$\boldsymbol{k}^{\prime}$} \\
\cline { 2 - 3 } \multicolumn{1}{c|}{} & MIP & NIP & \\
\hline Fluorene & 0.11 & 0.15 & $\mathbf{0 . 7 3}$ \\
\hline Phenanthrene & 1.33 & 0.02 & $\mathbf{6 6 . 5}$ \\
\hline Anthracene & 0.03 & 0.63 & $\mathbf{0 . 0 5}$ \\
\hline Fluoranthene & 1.39 & 0.76 & $\mathbf{1 . 8 3}$ \\
\hline Pyrene & 0.90 & 0.47 & $\mathbf{1 . 9 1}$ \\
\hline Chrysene & 0.38 & 0.62 & $\mathbf{0 . 6 1}$ \\
\hline Dibenzo(a,h)anthracène & 2.60 & 4.30 & $\mathbf{0 . 6 0}$ \\
\hline
\end{tabular}

For e-MIP-VFc-EDMA the low values of selectivity coefficients (k) indicated a poor recognition effect of $\mathrm{BaP}$ compared to other PAHs. The low range of $\mathrm{k}$ values is in agreement 
with the very similar aromatic structures of $\mathrm{BaP}$ and other PAHs, and the lack of specific chemical functionalities for such compounds. For phenanthrene, fluoranthrene and pyrene the relative selectivity coefficients $\mathrm{k}^{\prime}$, defined as the ratio of $\mathrm{k}(\mathrm{e}-\mathrm{MIP}) / \mathrm{k}(\mathrm{e}-\mathrm{NIP})$, were in favor of the imprinted polymers with an important effect in the case of phenanthrene. This still showed the imprinting effect and spoke in favor of specific interactions between $\mathrm{BaP}$ and the vinylferrocene monomer.

\subsection{Benzo[a]pyrene electrochemical detection}

Carbon paste was chosen to immobilize e-MIP and e-NIP for electrochemical characterizations. By this way, it was very simple and easy to fabricate modified electrode and it presented other advantages such as stability in various solvents, relatively lowbackground characteristics and a low residual current [21]. Only e-MIP/e-NIP based on VFcEDMA and VFc-4VP-EDMA were tested. For each polymer, a mixture of e-MIP or e-NIP with carbon paste (CPE) $(1: 4, \mathrm{w} / \mathrm{w})$ was prepared and put in a $5 \mathrm{~mm}$ diameter empty working electrode. After drying under vacuum, the carbon paste custom working electrode was polished and used in a classical three electrodes cell equipped with platinum as counter electrode and Saturated Calomel Electrode (SCE) as reference.

As expected anodic SWV scans for e-MIP-CPE and e-NIP-CPE based on VFc-EDMA showed one electron oxidation peak of ferrocene at 0.42 and $0.43 \mathrm{~V}$ vs SCE, respectively (Figure 5). For e-MIP-CPE/e-NIP-CPE based on VFc-4VP-EDMA a positive shift of around $100 \mathrm{mV}$ of oxidation peak was observed compared to VFc-EDMA electrode and could be attributed to an electron withdrawing effect of 4VP on ferrocenyl group by pi-pi interactions. Current intensity of anodic peaks for VFc-4VP-EDMA-CPE polymers was less intense in good agreement with the less quantity of ferrocenyl groups in these copolymers. In all cases, addition of $\mathrm{BaP}$ in the electrolytic solution leads to a decrease of current intensity with a more important impact for copolymers based on VFc-EDMA. 

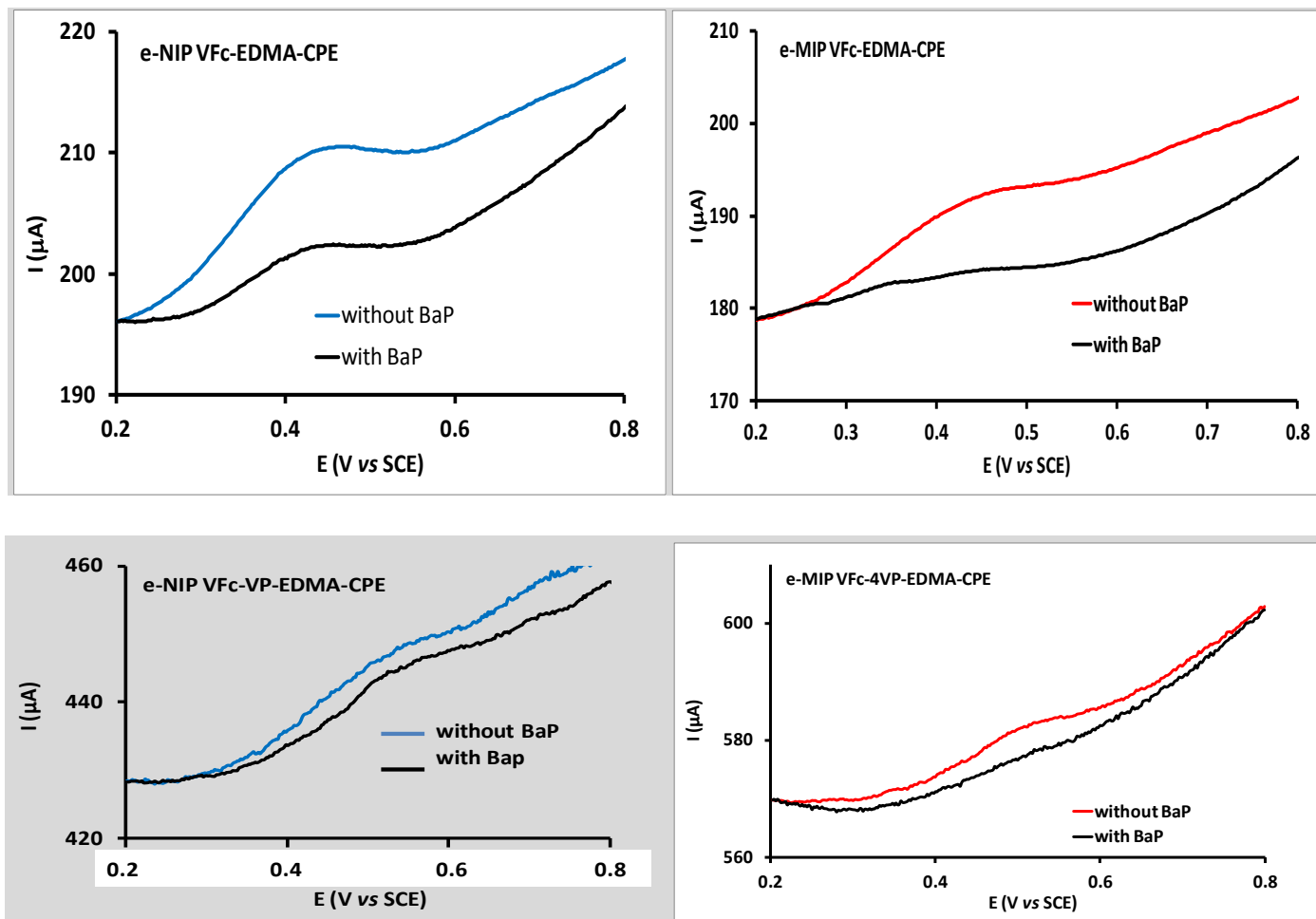

Figure 5. SWV of e-MIP-CPE/e-NIP-CPE with and without BaP (1 mg/L) after 4h. (a) e-MIP VFc-EDMA-CPE, (b) e-NIP VFc-EDMA-CPE, (c) e-MIP VFc-4VP-EDMA-CPE and (d) eNIP VFc-4VP-EDMA-CPE

Working electrodes with e-MIP or e-NIP were immersed in $5 \mathrm{~mL}$ of electrolyte solution in the presence of increasing concentration of $\mathrm{BaP}$ from 0 to $4.5 \mathrm{mg} / \mathrm{L}(18 \mu \mathrm{mol} / \mathrm{L})$ for 4 hours to reach adsorption equilibrium and the response of the electrode was is registered (Figure 6). The intensity of the oxidation current was compared with that obtained in the absence of BaP. The increase of the normalized value of the oxidation peak current was proportional to the concentration of $\mathrm{BaP}$ added in the solution $\left(\mathrm{R}^{2}>0.989\right)$. The slope of this linear function is was $1.12 \mu \mathrm{mol} / \mathrm{L} / \%$ for the e-MIP VFc-EDMA-CPE and $0.11 \mu \mathrm{mol} / \mathrm{L} / \%$ for the e-MIP VFc4VP-EDMA-CPE indicating that the first one is was more sensitive to the presence of $\mathrm{BaP}$. For both couples, e-MIP-CPEs had higher sensitivity in the presence of BaP than the corresponding e-NIPs-CPE. The ratio slope e-MIP-CPE/slope e-NIP-CPE was 1.4 for VFcEDMA-CPE and 1.9 for VFc-4VP-EDMA-CPE. The limits of detection calculated for e-MIP VFc-EDMA-CPE and e-NIP VFc-EDMA-CPE were found to be 0.28 and $0.29 \mathrm{mM}$ of BaP, respectively. The same calculation for e-MIP VFc-4VP-EDMA-CPE and e-NIP VFc-4VPEDMA-CPE lead to 0.74 and $0.78 \mathrm{mmol} / \mathrm{L}$ of $\mathrm{BaP}$, respectively. Limits of quantification obtained for e-MIP VFc-EDMA-CPE, e-NIP VFc-EDMA-CPE, e-MIP VFc-4VP-EDMACPE and e-NIP VFc-4VP-EDMA-CPE were 0.93, 0.95, 2.47 and $2.59 \mu \mathrm{mol} / \mathrm{L}$, respectively. 
Adsorption studies have revealed a maximum adsorption capacity similar for both polymers e-MIP VFc-EDMA and e-MIP VFc-4VP-EDMA (7.3 and $8.5 \mathrm{mg} / \mathrm{g}$, respectively) but when incorporated inside electrodes, electrochemical analyses proved that e-MIP VFc-EDMA-CPE and corresponding e-NIP was more sensitive to the presence of $\mathrm{BaP}$ compared to polymers based on VFc-4VP-EDMA. These results were in good agreement with the amount of integrated vinylferrocene in these polymers. Indeed, the VFc was present at 18 to $19 \mathrm{~mol} \%$ in the VFc-EDMA, unlike VFc-4VP-EDMA in which it was present only to $8 \%$ molar. The amount of VFc had a direct impact on the oxidation current value of the polymer, the higher its value, the greater the oxidation current was important.

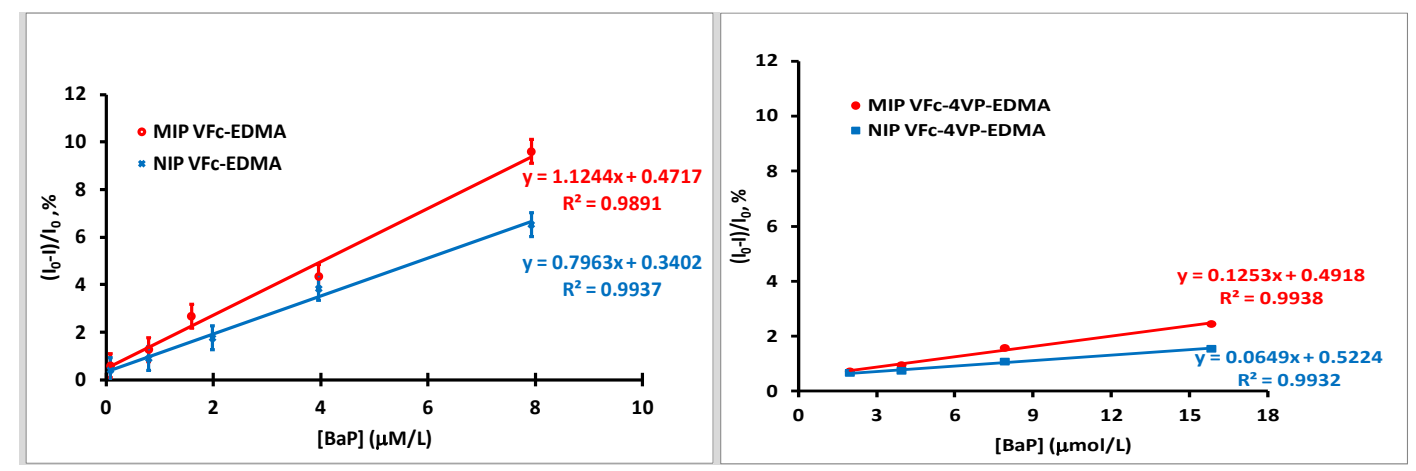

Figure 6. Normalized current curves where I was the current obtained in presence of $\mathrm{BaP}$ and $\mathrm{I}_{0}$ the current before $\mathrm{BaP}$ addition (formulated in percentage in function of added $\mathrm{BaP}$ ). (a) VFc-EDMA-CPE et (b) VFc-4VP-EDMA.

\section{Conclusion}

In conclusion, original electrochemical molecularly imprinted polymers (e-MIPs) with redox binding cavities to detect benzo(a)pyrene $(\mathrm{BaP})$ were synthesized integrating the vinylferrocene (VFc) redox tracer with or without 4-vinylpyridine (4-VP) as comonomer and ethylene glycol dimethacrylate (EDMA) or divinylbenzene (DVB) as crosslinker, in the same time with a hybridation oven. As expected, using an aromatic comonomer or crosslinker increase adsorption capacities by a factor 6-8 compared to the reference polymer VFc-EDMA but, unfortunately, not the imprinting factor. Electrochemical measurements for e-MIP/e-NIP for polymers based on VFc-EDMA and VFc-4VP-EDMA revealed that the first one has the best LOD with a value of $0.93 \mu \mathrm{mol} / \mathrm{L}$. Knowing that these carbon paste electrodes are not optimized, the strategy reported in the present article is very promising for future applications in PAHs sensors fields and can be, moreover, applied to a wild range of analytes presenting or lacking redox properties. 


\section{AUTHOR INFORMATION}

Corresponding Authors

C. Branger: phone +33 494146729 E-Mail: branger@univ-tln.fr;

H. Brisset: phone +33 494146724 E-Mail: brisset@univ-tln.fr.

\section{ACKNOWLEDGMENT}

The authors acknowledge financial support by the "Société du Canal de Provence" and by the Regional Council of Provence Alpes Côte d'Azur (France). Authors are also thankful financial support from the Academy of Finland, the Research Foundation of the Lappeenranta University of Technology, the Magnus Ehrnrooth Foundation, and the Finnish Cultural Foundation, South Karelia Regional fund. 
[1] K. Haupt and K. Mosbach, Molecularly Imprinted Polymers and Their Use in Biomimetic Sensors, Chem. Rev. 100 (2000) 2495-2504.

[2] L. Ye and K. Haupt, Molecularly imprinted polymers as antibody and receptor mimics for assays, sensors and drug discovery, Anal. Bioanal. Chem. 378 (2004) 1887-1897.

[3] G. Vlatakis, L. I. Andersson, R. Müller, and K. Mosbach, Drug assay using antibody mimics made by molecular imprinting, Nature 361 (1993) 645-647.

[4] K. Haupt, Molecularly imprinted polymers: the next generation, Anal. Chem. 75 (2003) 376A-383A.

[5] B. Tse Sum Bui, K. Haupt, Molecularly imprinted polymers: synthetic receptors in bioanalysis, Anal. Bioanal. Chem. 398 (2010) 2481-2492.

[6] L. Uzun, A.P.F. Turner, Molecularly-imprinted polymer sensors: realising their potential, Biosens. Bioelectron. 76 (2016) 131-144.

[7] F. Canfarotta, R. Rapini, S. Piletsky, Recent advances in electrochemical sensors based on chiral and nano-sized imprinted polymers, Curr. Opin. Electrochem. 7 (2018) 146-152.

[8] C. Branger, H. Brisset, D. Udomsap, University of Toulon. French Patent. FR 1000175817. 21/12/2012. PCT/IB2013/ 061196 - 20/12/2013. US Patent 20,150,344,607, 2015

[9] D. Udomsap, C. Branger, G. Culioli, P. Dollet, H. Brisset, A versatile electrochemical sensing receptor based on a molecularly imprinted polymer, Chem. Commun. 50 (2014) 7488-7491.

[10] V. Mba Ekomo, C. Branger, R. Bikanga, A.-M. Florea, G. Istamboulie, C. CalasBlanchard, T. Noguer, A. Sarbu, H. Brisset, Detection of Bisphenol A in aqueous medium by screen printed carbon electrodes incorporating electrochemical molecularly imprinted polymers, Biosensors and Bioelectronics 112 (2018) 156-161.

[11] V. Mba Ekomo, C. Branger, R. Bikanga, G. Istamboulie, C. Calas-Blanchard, T. Noguer, H. Brisset, Screen printed carbon electrodes incorporating electrochemical molecularly imprinted polymers to detect pollutant, $17^{\text {th }}$ International Meeting on Chemical Sensors (2018) 219-220. DOI 10.5162/IMCS2018/EC2.2

[12] E Mazzotta, A Turco, I Chianella, A Guerreiro, SA Piletsky, C Malitesta, Solid-phase synthesis of electroactive nanoparticles of molecularly imprinted polymers. A novel platform for indirect electrochemical sensing applications, Sensors and Actuators B: Chemical 229 (2016) 174-180. 
[13] S. Rebocho, C.M. Cordas, R. Viveiros, T. Casimiro, Development of a ferrocenyl-based MIP in supercritical carbon dioxide: Towards an electrochemical sensor for bisphenol A, J. Supercrit. Fluids 135 (2018) 98-104.

[14] J.P. Lai, R. Niessner, D. Knopp, Benzo[a]pyrene imprinted polymers: synthesis, characterization and SPE application in water and coffee samples, Anal. Chim. Acta 522 (2004) 137-144.

[15] W.-H. Li, H.D.H. Stöver, Porous monodisperse poly(divinylbenzene) microspheres by precipitation polymerization, J. Polym. Sci. Part Polym. Chem. 36 (1998) 1543-1551.

[16] M.H. George, G.F. Hayes, Free radical polymerization of vinylferrocene. I. Kinetics, J. Polym. Sci. Polym. Chem. Ed. 13 (1975) 1049-1070.

[17] C.U. Pittman Jr, The Discovery of Metallocene- and Metallocene-Like Addition Polymers, Inorg. Organomet. Polym. Mater. 15 (2005) 33-55.

[18] C. Hinz, Description of sorption data with isotherm equations, Geoderma 99 (2001) 225243.

[19] G. Limousin, J.-P. Gaudet, L. Charlet, S. Szenknect, V. Barthès, M. Krimissa, Sorption isotherms: A review on physical bases, modeling and measurement, Appl. Geochem. 22 (2007) 249-275.

[20] W.L. Ho, T.C. Lin, Y.Y. Liu, J.A. Chen, Analysis of smoke PAHs from selected Taiwanese cigarettes by using molecular imprinting polymers, J. Environ. Sci. Health Part A 45 (2010) 211-223.

[21] I. Švancara, K. Vytřas, K. Kalcher, A. Walcarius, and J. Wang, Carbon Paste Electrodes in Facts, Numbers, and Notes: A Review on the Occasion of the 50-Years Jubilee of Carbon Paste in Electrochemistry and Electroanalysis, Electroanalysis 21 (2009) 7-28. 